\title{
Expanding the Paradigm: Countering Violent Extremism in Britain and the Need for a Youth Centric Community Based Approach
}

\section{by Samuel Tyler Powers}

\section{(cc) $\mathrm{BY}$}

This work is licensed under a Creative Commons Attribution 3.0 License.

\begin{abstract}
In recent years, both academics and politicians alike have struggled to develop a coherent strategy on how to hone in the threat posed by Islamic extremists at home and abroad. This issue has taken center stage in recent months with the emergence of the Islamic State (IS). This article will explore the UK's experience with trying to contain Islamic extremism, focusing particularly on the role youth development may play in future endeavors.
\end{abstract}

Keywords: Jihadism, Homegrown Extremism, Islamic State, Prevent Strategy, United Kingdom

\section{Introduction}

ollowing the emergence of the IS menace this year, there has been a groundswell of inquiry to better understand why British nationals would travel to the frontlines of some of the most dangerous places in the world to fight jihad. Unlike the United States, the UK has had a great deal of experience in trying to contain radical elements within its borders to prevent such activity. Revisiting this experience with Islamic extremism is critical to crafting appropriate responses to preventing future radicalization and attacks both at home and abroad.

\section{The Prevent Strategy: Critiques of Government Approaches at Countering Violent Islamic Extremism}

Emerging initially in the wake of the 7/7 bombings, the Prevent strategy continues to remain Britain's core policy aimed at tackling "the ideological challenge faced from terrorism and aspects of extremism, and the threat faced from those who promote these views." [1] Since its initial implementation, the strategy has been revised various times to adapt to critiques emanating from the Muslim community that the strategy is merely serving as a means to inter alia collect intelligence on Muslims. [2] The most recent revisions carried out after a 2011 review expand the aim of the program to "deal more proportionately with all kinds of terrorist threats and concentrate on some aspects of non-violent extremism that create an environment conducive to radicalization." [3] The new strategy also clearly states that support will be cut to those organizations that oppose "fundamental and universal" British values including certain Salafi organizations.[4] While some support such changes, many disagree including Muslim community leaders such as Mohammed Shafiq, and terrorism expert Dr. Robert Lambert, former head of the London Met Police's Muslim Contact Unit (MCU). Both Shafiq and Lambert view such a shift as regressive and damaging to years of work to weed out AQ operatives amidst conservative religious circles including Salafis in the Brixton and Finsbury Park areas. [5] [6] It remains exceedingly difficult to gauge the real success of Prevent, as very few effective tools aside from 


\section{Journal of Terrorism Research}

anecdotal evidence exist to measure ones vulnerability to becoming involved in extremism and the effect certain programs may have at reversing such processes.[7] Organizations including the Youth Justice Board for England and Wales (YJB) have citied the need to provide Prevent projects with an evaluation process. According to a report issued by YJB in 2012 it is important to,

Identify those young people who are most susceptible to being radicalized, and having done so, being able to measure effectively the 'distance traveled' in reducing the their vulnerability, and hence, the impact of the interventions to which they have been exposed. [8]

While developments within Prevent, such as the Channel project have been created to refine the focus of the program to "identify individuals at risk of being drawn into terrorism; assess the nature and extent of that risk; and develop the most appropriate support plan for the individuals concerned," it is unclear as to whether such programs have actually been successful in deterring extremist ideology.[9] Channel is viewed by many as a substantial addition to Prevent, as it stresses collaboration with communities in finding early warning signs of those heading down the path towards extremism.[10] A 2011 report released by the Police Science Institute at Cardiff University (UPSI) attests that in the case of the 7/7 attacks such an early intervention system could have prevented the bombers from mobilizing.[11] As of July 2013, of the 2,653 referrals to the program, 67 percent of those taken into Channel were Muslim and the majority were youth.[12]

While those including the 7/7 bombers clearly demonstrate a desire to wage violence, it is unclear as to whether the other referrals to Channel have fit such a tight model. Skeptics of the Prevent strategy, including Dr. Paul Thomas at the University of Huddersfield, argue that it is difficult at best to ascertain whether a youth is vulnerable to extremism. He also posits that such a process is often not linear.[13] In addition, as of 2011, conservative Islamist groups and those practicing Salafism, no longer had the ability to reference youth to the Channel program, minimizing the ability of said groups to weed out nefarious actors who have historically threatened their communities.[14]

\section{“Things do Change": A Case Study of Community Based Projects Aimed at Tackling Religious Extremism}

In interviews conducted for this article, the majority of respondents expressed their belief that Muslim communities must play a larger role in weeding out extremists who prey on youth in particular. In investigating the Prevent program, I traveled to Halifax, in West Yorkshire, to meet with a Muslim community officer who had received initial monies from Prevent's Pathfinder fund.[15]

Sail Suleman, a Muslim of Pakistani descent, who holds the title of Interfaith Counselor at the Calderdale city council, developed a training program in 2009 know as "Things Do Change," whose stated goal is to "prevent violent extremism amongst young people and encourage tolerance and community cohesion." [16] The creation of "Things Do Change" was inspired directly by the 7/7 attacks. Three of the bombers involved in the attacks including Shezad Tanweer, Mohammed Siddique Khan and Hasib Hussain, hailed from West Yorkshire, spawning interest by local government in creating a program to deter Islamic extremist ideology in particular.[17]

“Things do Change" is made up of ten modules, including guided classroom discussion as well as DVD's and posters, all designed to encourage debate amongst a diverse group of individuals aged 11-19.[18] While offering a discussion forum around issues pertaining to religious extremism, the resource pack also asks students to prepare bespoke projects aimed at minimizing the appeal of extremism by increasing knowledge of Britain's multicultural society. Such projects include an exploration of the maxim "Do unto others as you 


\section{Journal of Terrorism Research}

would have them do unto you," highlighting that the majority of world religions, possess a similar apothegm, something that most respondents were unaware of.[19]

After establishing a basis of mutual understanding, "Things do Change" begins to discuss more sensitive issues including citizenship, social cohesion, and the impact of the 7/7 bombings. Suleman commented that in discussing more delicate issues, tensions were quick to arise; it was critical to have an individual who understood local needs and community dynamics to guide the debate.[20] In evaluations of Prevent conducted by the UPSI for the Association of Police Chief Officers (ACPO) in 2011, harnessing voices with experience in community organizing was sighted as a recommendation for future initiatives.

There is some evidence that the capacity of communities to self-mobilise or engage in co-productive working may be shaped, at least in part, by the presence or otherwise of individuals with professional community organising skills. This would suggest that enlisting such individuals at a local level into the Prevent agenda could be an important objective for the police.[21]

In a more controversial module, students are asked to present a project on the $7 / 7$ attacks from the perspective of the bombers themselves, in order to unpack the motives leading the young men to commit such actions. This component caused an instant stir, leading some of the projects initial supporters, including multiple members of Parliament, to pull their support for the project all together.[22] Others, including Tahir Alam of the Muslim Council of Britain and Jonathan Bartley of the think tank Ekklesia defended this component, viewing it as integral to exploring what leads one down the road to extremism. In a 2009 interview, Bartley stated,

We need a generation that can understand what motivates, the other... They need to ask what breeds the anger that in turn produces an unaccountable minority willing to use terror tactics. [23]

While containing elements that some may view as controversial, "Things do Change," addresses a key void highlighted in critiques of other Prevent programs such as the lack of bridge building between communities and the need to address enclavisation in immigrant populations. By establishing dialogue across communities, Suleman has been able to initiate a discussion on sensitive topics, such as racism and foreign policy that are often seen as factors fueling extremism. He has also hosted cultural events and interfaith discussions that bring diverse groups to the table, and go well beyond token expressions of solidarity after an incident like a terrorist attack.

Suleman himself places much of the program's success on the fact that over the years he has developed an organic report with the multi-ethnic community in which he is from, thereby becoming a voice for Muslims and successfully bridging the gap between "police, Masjids and the authorities." [24] While Suleman's work stems initially from Prevent funding, the fact that the project is managed by local actors, knowledgeable with the local milieu, amplifies its impact much more effectively when discussing sensitive subjects such as multiculturalism, democracy, and citizenship.[25]

While audits into the program remain difficult to obtain, a 2009 review of the project by the Calderdale Council Head of Housing and Community Support applauded the project, describing it as,

an excellent tool in taking forward this leadership role and prompting discussion and debate on community cohesion issues which are so vital to the future of society in Britain.[26]

The success of the project is also evident in its wide scale usage across Muslim madrassas and mosques in West Yorkshire. The resource pack has also been purchased by diverse groups including multiethnic schools in Sandwell, Birmingham, and Lancashire and police forces in Greater Manchester, Metropolitan and London 


\section{Journal of Terrorism Research}

Thames Valley.[27] The department for children, schools and families (DCSF) recommended the pack to teachers as part of its online guidance on how schools can help tackle extremism.[28]

\section{Credibility and Accountability: Re-Evaluating the Role of Government in Supporting CVE Initiatives}

Suleman, UPSI, as well as various scholars including Lambert and Weeks attest that in the majority, certain Muslim populations prefer to rely on local means, rather than government, to solve problems within a community.[29] In an interview conducted by Innes Martin at UPSI with a self-proclaimed moderate Muslim, it was made clear that in resolving a problem, he would look first to "family, then the community then the Imam." [30] This sentiment was echoed by many Muslim professionals interviewed for this article. [31] While such approaches cannot be seen in a vacuum, after conducting over 95 interviews with Muslim community members, UPSI reiterated that

It remains the case that Muslim communities continue to express a preference for using their own informal social control resources to solve a problem when this is (or at least is believed to be) feasible.[32]

It is in this milieu that the importance of credibility becomes a critical component in addressing the issue of extremism amongst youth in particular. While for the most part, perceptions of the police within the Muslim community in the UK remain positive, there is a clear deficit in trust amongst youth. [33] In a project undertaken in 2009, in the London borough of Barnet, young Muslims expressed suspicion, stating that police should "treat people with respect and stop discriminating," and that they should "promote a greater sense of interaction with the communities...recruit more ethnic minorities into the areas you police, especially more Muslims." [34] Such attitudes were confirmed by Suleman and Shafiq, as remaining prevalent amongst youth, even amidst improvements in community-police relationships.

According to reports by UPSI, some Prevent programs still lack a genuine understanding of community needs leading populations to remain skeptical of CVE work and policing efforts.[35] This suspicion is heightened substantially when an event occurs in which tactical police measures detailed in CONTEST's Pursue strategy, eclipse or fail to engage Prevent teams in planned operations. Suleman detailed a case in which a local Imam came to him to express anger that "spies" had been planted by authorities in a local masjid.[36] Such occurrences, whether real or unreal, made it hard to reassure the community that police and those involved in Prevent were truly invested in helping fight extremism and not just "snooping" on Muslims. [37] UPSI highlighted that in 2010, Prevent work ongoing in Birmingham, was brought to a standstill when advanced CCTV and Automatic Number Plate Recognition (ANPR) cameras were installed through an initiative know as Project Champion, that, in reality, was purposed for CT use rather than quotidian criminal surveillance. Prevent officers in the field were unaware of such activity taking place and thus, once the story was blown, their relationships with community members were compromised almost instantly. One community member described how such surveillance undermined the efforts of the police by stating, "the relationship between the police and the community was severed, you know there was a void left there, it was like total mistrust." [38]

While such damage is not entirely irreparable, the incidents detailed above show how critical local voices can be in maintaining the success of CVE initiatives in the long run, particularly in moments of community disenfranchisement. For some scholars, including Arjun Appadurai, the empowerment of local voices takes on an especially critical role in diaspora communities, where mass media has maintained ties with the parent country, but has also created a "disjuncture between spatial and virtual neighborhoods." [39] This 


\section{Journal of Terrorism Research}

disconnectedness is evidenced, for example, in older generations of Somali's living in the US, who prefer to maintain ties with their home culture, and stigmatize those who try to integrate into the local milieu.[40]

\section{Enclavisation and Exclusion: What Can Be Learned from Community Projects Not Focused on Religous Extremism?}

While trust building and integration of local voices may be something that is best executed from within, there are ways that government and NGO's can help facilitate such a process. As a youth mentor in New York's inner city, I was able to partake in an initiative spearheaded by an organization known as the All Stars Project titled Operation Conversation: Cops and Kids, which set forth to "foster positive interactions between the police and inner-city youth." While dealing with a different demographic (most youth involved in the program are black or Latino), such trust building activities could resonate profoundly with a Muslim youth bulge in the UK that remains suspicious of law enforcement officers.

To begin, the founder of the project, Dr. Lenora Fulani, asks police officers and kids to comment on "how they feel about being there with the other and something that they always wanted to get off their chest." [41] Cops and Kids then proceeds with a series of workshops that use games, improvisation workshops, and performance arts to directly engage police officers and youth. The project has been so successful, that, as of October 2011, the NYPD incorporated the initiative into its training for all new cadets. [42] While such an initiative will certainly face new challenges in working with a distinctly different demographic in the UK, it could serve as a useful tool in addressing the strained relationship between police and Muslim youth. Although an extensive amount of youth programs exist dealing with crime, research shows that collaboration between the police and youth in the UK in such an intimate fashion has not been explored at the as of yet.

Before concluding this section, it is worth revisiting the issue of enclavisation as an important factor in breeding extremism. While the researcher cannot claim that there is a conclusive link between residing in an ethnically or religiously homogenous neighborhood, and joining an extremist organization, radical preachers, including Abu Hamza al-Masri, have preyed on recent immigrants in particular living in such areas.[43] Imam Khalid Latif, headed Imam of the NYPD and New York University, as well as various other Muslim professionals, reiterated this point and detailed that the issue was most acute in conservative Muslim circles in which young boys often spend time between mosques run by older Imam's unfamiliar with "western society" and nuclear families who lack English language skills. [44] This type of enclavisation is not unique to Muslim communities. Such a disconnect has been blamed for low levels of performance in schools in black and Latino neighborhoods in the United States as well.[45] In exposing homogenous community groups to various faiths and ethnicities as "Things Do Change" has done, levels of understanding amongst youth become intrinsic even while the nuclear family or local community may remain skeptical. Various studies have made clear that such interethnic contact was amongst one of the largest predictors of a youth's positive attitude change.[46]

Before writing this article, the author had undergone extensive experience taking part in inter-faith and inter-ethnic exercises with youth from various communities. One such initiative spearheaded by the New York City branch of a non-profit named Boy's Hope Girls Hope (BGHGNY), was titled “Guess Who's Coming to Dinner," which brings majority black and Latino youth together with professionals from mixed race backgrounds to discuss careers and life choices over a two-hour dinner. While seemingly simple, it was quite noticeable how after participating in the program for a short duration, a teen's attitude was markedly shifted toward a positive embrace of other cultures outside of the milieu with which $\mathrm{s} / \mathrm{he}$ is familiar. Interest 


\section{Journal of Terrorism Research}

in engaging in an environment that otherwise would have been unexposed is heightened, and enduring connections are established, according to BHGHNY's CEO, Brad Zervas. [47] In minimizing the narrative of groups like Al Qaeda and IS, which advocate for ethno-religious enclaves to remain homogenous, the impact of such programs should not be discounted.

\section{Conclusions}

In summary, we can distill various key take aways from the UK's experience with CVE work since the 7/7 attacks. Firstly, as various successes and failures of Prevent projects have shown us, the marginalization of community voices in the decision making process makes long term project sustainability less likely.

Secondly, a lack of transparency and coordination between Prevent officials and other CONTEST strands may breach trust, particularly when tactical CT measures are conducted under the guise of other initiatives. This was evidenced by the ultimate failure of Project Champion that eclipsed existing CVE work by prioritizing tactical surveillance measures.

Thirdly, In approaching target communities, it has proven effective, as highlighted by Innes et al to utilize existing community members rather than relying on those who are unaccustomed to local nuances. "Things Do Change" has shown that throughout the entirety of CVE projects, an interfaith and interethnic component will help to develop a more diverse understanding of a youth's larger surroundings, thereby undermining the voices of extremists trying to polarize communities on religious grounds.

About the author: A native of New York City, Samuel Powers received a B.A. in Diplomacy and World Affairs from Occidental College in 2011 during which time he interned for Soliya, a UN sponsored initiative that uses social media and film making to promote cross-cultural understanding between the West and the Muslim world. Powers spent five months in Bolivia producing and directing an award-winning documentary about the role of development in the War on Drugs. He is also a researcher at the counter terrorism desk at Wikistrat, a geostrategic analysis firm. In 2014, Powers received his M.S., with distinction, in transnational security studies from New York University. His research interests include Islamic extremism, particularly Salafi Jihadism, as well as homegrown terrorism and narcoterrorism in Latin America. He conducted field research in London in 2013 after receiving a research grant towards completion of his thesis that focused on the role of youth development in deterring the influence of Al Qaeda in the US and UK. He has published a range of articles on security issues in the Sahel region, as well as articles on cyber terrorism and the war on drugs in the Andes.

\section{Notes}

[1] HM Government 'Prevent Strategy' (London, HM Government, 2011). 1

[2] Ouston, Martyn. “The 'Prevent' Strategy in Bedfordshire.” Diss. Trinity St. Davids, Wales, 2013. Print. 46

[3] HM Government 'Prevent Strategy' (London, HM Government, 2011). 1.

[4] Gardham, Duncan. “Counter-terrorism Projects worth $£ 1.2 \mathrm{~m}$ Face Axe as Part of End to Multiculturalism.” The Telegraph. Telegraph Media Group, 09 July 0032. Web. 26 Apr. 2014.

[5] Lambert, Robert. Countering Al-Qaeda in London: Police and Muslims in Partnership. London: Hurst \&, 2011. 216. Print.

[6] “Interview with Mohammed Shafiq." Personal interview. 12 February. 2014. 


\section{The Centre for the Study of Terrorism and Political Violence Journal of Terrorism Research}

[7] Christmann, Kris. "Preventing Religious Radicalisation and Violent Extremism: A Systematic Review of the Research Evidence." Review. Youth Justice Board for England and Wales 2012: 10-21. 16

[8] ibid, 79

[9] Whitehead, Tom. "Hundreds of Children Identified as Extremism Risk." The Telegraph. Telegraph Media Group, 22 July 2013. Web.

[10] ibid

[11] Innes, Martin, Helen Innes, Suraj Lakhani, and Trudy Lowe. Assessing the Effects of Prevent Policing A Report to the Association of Chief Police Officers. Rep. Cardiff: Universities' Police Science Institute Cardiff University, 2011. March. 2011. Web

[12] Whitehead, Tom. "Hundreds of Children Identified as Extremism Risk.” The Telegraph. Telegraph Media Group, 22 July 2013. Web.

[13] “Interview with Dr. Paul Thomas." Personal Interview. 11 February. 2014

[14] “Interview with Dr. Douglas Weeks." Personal Interview. 15 February. 2014.

[15] Pathfinder fund is an element of Prevent in which funds are allocated to local efforts that are aimed at "preventing violent extremism and creating a situation where Muslim communities reject and actively condemn violent extremism and seek to undermine and isolate violent extremists" (Source: Home Office Archives)

[16] Shepherd, Jessica. "Pupils Asked to See Bombers' Point of View.” The Guardian. N.p., 19 Feb. 2009. Web

[17] ibid

[18] “Interview with Sail Suleman.” Personal Interview. 12 February. 2013.

[19] ibid

[20] ibid

[21] Innes, Martin, Helen Innes, Suraj Lakhani, and Trudy Lowe. Assessing the Effects of Prevent Policing A Report to the Association of Chief Police Officers. Report. Cardiff: Universities' Police Science Institute Cardiff University, 2011. March. 2011. Web. 5

[22] Shepherd, Jessica. "Pupils Asked to See Bombers' Point of View." The Guardian. N.p., 19 Feb. 2009. Web

[23] ibid

[24] Innes, Martin, Helen Innes, Suraj Lakhani, and Trudy Lowe. Assessing the Effects of Prevent Policing A Report to the Association of Chief Police Officers. Report. Cardiff: Universities' Police Science Institute Cardiff University, 2011. March. 2011. Web. 5

[25] ibid

[26] Andrew, Pitts. Report to Scrutiny Panel: Community Cohesion and Preventing Violent Extremsim. Rep. no. 9. N.p.: Calderdale Council, 2009. Print.

[27] Shepherd, Jessica. "Pupils Asked to See Bombers' Point of View." The Guardian. N.p., 19 Feb. 2009. Web

[28] Innes, Martin, Helen Innes, Suraj Lakhani, and Trudy Lowe. Assessing the Effects of Prevent Policing A Report to the Association of Chief Police Officers. Report. Cardiff: Universities' Police Science Institute Cardiff University, 2011. March. 2011. Web. 5

[29] ibid

[30] ibid,32.

[31] “Interview with Imam Khalid Latif.” Personal interview. 13 January. 2013.

[32] Innes, Martin, Helen Innes, Suraj Lakhani, and Trudy Lowe. Assessing the Effects of Prevent Policing A Report to the Association of Chief Police Officers. Rep. Cardiff: Universities' Police Science Institute Cardiff University, 2011. March. 2011. Web. 5

[33] ibid

[34] Ryan, Louise, Eleonore Kofman, and Ludovica Banfi. MUSLIM YOUTH IN BARNET: EXPLORING IDENTITY, CITIZENSHIP AND BELONGING LOCALLY AND IN THE WIDER CONTEXT. Middlesex University Social Policy Research Centre, June 2009. Web. 7 


\section{The Centre for the Study of Terrorism and Political Violence Journal of Terrorism Research}

[35] Innes, Martin, Helen Innes, Suraj Lakhani, and Trudy Lowe. Assessing the Effects of Prevent Policing A Report to the Association of Chief Police Officers. Rep. Cardiff: Universities' Police Science Institute Cardiff University, 2011. March. 2011. Web. 5

[36] “Interview with Sail Suleman.” Personal Interview. 12 February. 2013.

[37] Ibid

[38] Innes, Martin, Helen Innes, Suraj Lakhani, and Trudy Lowe. Assessing the Effects of Prevent Policing A Report to the Association of Chief Police Officers. Report. Cardiff: Universities' Police Science Institute Cardiff University, 2011. March. 2011. Web. 23

[39] Pearce, Lynne. “Diaspora.” M/C Journal, 2011. Web. 23 April. 2014

[40] Elliott, Andrea. "A Call to Jihad, Answered in America." The New York Times. The New York Times, 11 July 2009. Web. 23 April. 2014

[41] “Dr. Lenora Fulani.” Personal interview. 22 January. 2014.

[42] “Operation Conversation: Cops and Kids.” All Stars Project INC. N.p., n.d. Web. 07 April. 2014.

[43] Wojtowicz, Anna. Islamic Radicalization in the UK: Index of Radicalization. Rep. Herzlyia: International Policy Institute for Counter-Terrorism, 2012. Print. 41

[44] “Interview with Imam Khalid Latif." Personal Interview. 13 January. 2013.

[45] “Dr. Lenora Fulani.” Personal Interview. 22 January. 2014.

[46] Clément, R., R. C. Gardner, and P. C. Smythe. "Inter-ethnic Contact: Attitudinal Consequences." Canadian Journal of Behavioural Science/Revue Canadienne Des Sciences Du Comportement 9.3 (1977): 205-15. Print.

[47] “Interview with Brad Zervas." Personal Interview. 13 March. 2014. 